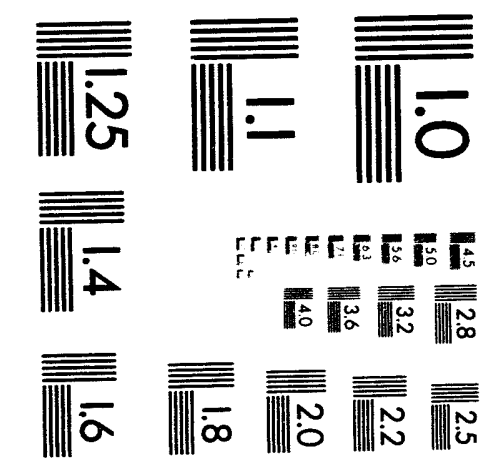



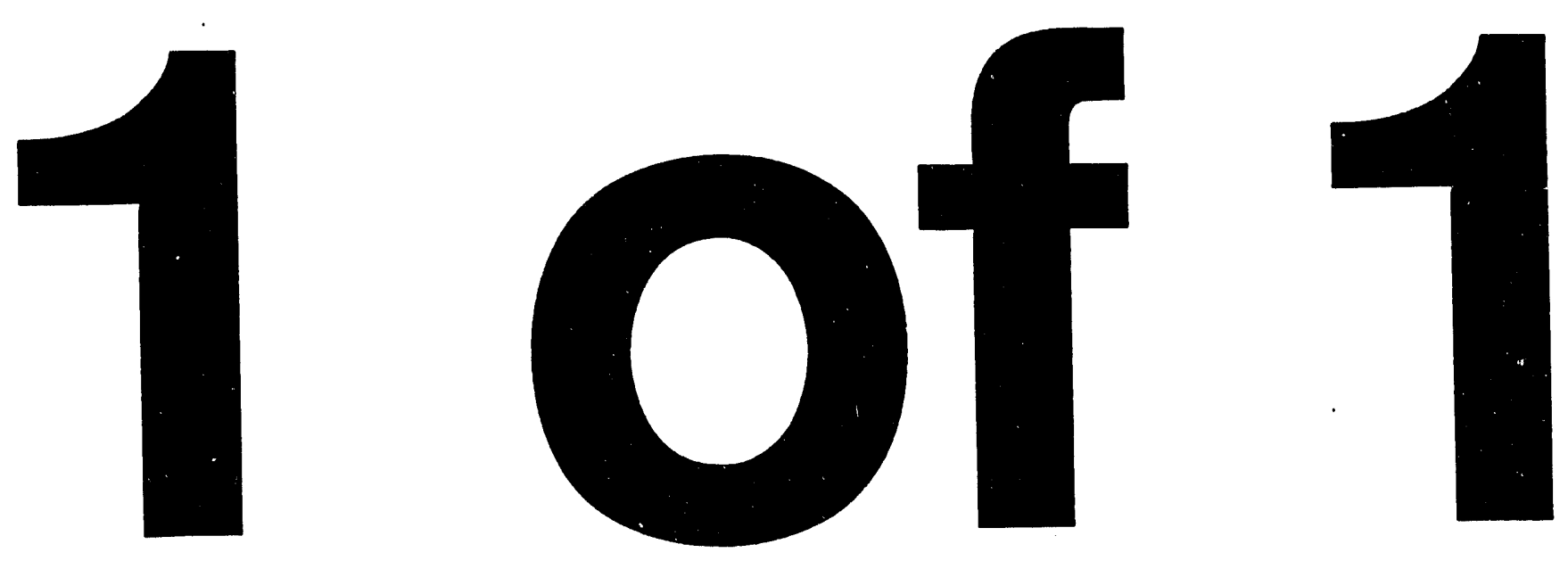


\title{
$\operatorname{Con}-940211--4$
}

BNL-NUREG-49797

\section{Detonation Cell Size Measurements and Predictions in Hydrogen-Air-Steam Mixtures at Elevated Temperatures}

\author{
G. Ciccarelli, T. Ginsberg, J. Boccio, and C. Economos \\ Brookhaven National Laboratory \\ Department of Advanced Technology \\ Safety and Risk Evaluation Division \\ Upton, NY 11973-5000, USA
}

Telephone: (516) 282-3906

Facsimile: (516) 282-2293

\section{Word Length:}

Text:

Figures: $200 \times 6=\underline{1,200}$ words

Total $=\quad 5,351$ words

\section{Presentation preference:}

Oral Presentation

Publication preference:

Combustion and Flame

\section{Code letters:}

\section{Experimental Data and Interpretation \\ 5.0 Detonations and Explosions \\ 5.1 Gas Phase Detonations}

\section{DISCLAIMER}

This report was prepared as an account of work sponsored by an agency of the United States Government. Neither the United States Government nor any agency thereof, nor any of their Government. Neither the United States Government nor any agency thes liability or responsibility for the accuracy, completeness, or usefulness of any information, apparatus, product, or process disclosed, or represents that its use would not infringe privately owned rights. Reference herein to any specific commercial product, process, or service by trade name, trademark, manufacturer, or otherwise does not necessarily constitute or imply its endorsement, recommendation, or favoring by the United States Government or any agency thereof. The views and opinions of authors expressed herein do nut necessarily state or reflect those of the United States Government or any agency thereof. 


\title{
Detonation Cell Size Measurements and Predictions in Hydrogen-Air-Steam Mixtures at Elevated Temperatures
}

\author{
G. Ciccarelli, T. Ginsberg, J. Boccio, and C. Economos \\ Brookhaven National Laboratory \\ Department of Advanced Technology \\ Safety and Risk Evaluation Division \\ Upton, NY 11973-5000, USA
}

\begin{abstract}
The present research reports on the effect of initial mixture temperature on the experimentally measured detonation cell size for hydrogen-air-steam mixtures. Experimental and theoretical research related to combustion phenomena in hydrogen-air-steam mixtures has been ongoing for many years. However, detonation cell size data currently exists for hydrogen-air-steam mixtures up to a temperature of only $400 \mathrm{~K}$. Severe accident scenarios have been identified for light water reactors (LWRs) where hydrogen-air mixture temperatures in excess of $400 \mathrm{~K}$ could be generated within containment. The experiments in this report focus on extending the cell size data base for initial mixture temperatures in excess of $400 \mathrm{~K}$.

The experiments were carried out in a $10-\mathrm{cm}$ inner-diameter, $6.1-\mathrm{m}$ long heated detonation tube with a maximum operating temperature of $700 \mathrm{~K}$ and spatial temperature uniformity of $\pm 14 \mathrm{~K}$. Detonation cell size measurements provide clear evidence that the effect of hydrogen-air initial gas mixture temperature, in the range $300 \mathrm{~K}-650 \mathrm{~K}$, is to decrease cell size and, hence, to increase the sensitivity of the mixture to undergo detonations. The effect of steam content, at any given temperature, is to increase the cell size and, thereby, to decrease the sensitivity of stoichiometric hydrogen-air mixtures. The hydrogen-air detonability limits for the $10-\mathrm{cm}$ inside-diameter test vessel, based upon the onset of single-head spin, decreased from 15 percent hydrogen at $300 \mathrm{~K}$ down to about 9 percent hydrogen at $650 \mathrm{~K}$. The one-dimensional ZND model does a very good job at predicting the overall trends in the cell size data over the range of hydrogen-air-steam mixture compositions and temperature studied in the experiments.
\end{abstract}




\section{Introduction}

The Three-Mile Island accident in 1979 demonstrated that hydrogen combustion could occur in the containment atmosphere of a water-cooled nuclear reactor in the event of a severe accident involving extensive reactor core damage [1]. As a result, intensive studies related to the combustion characteristics of mixtures of hydrogen, air, and steam were carried out during the 1980s. The studies attempted to characterize the potential modes of combustion and to develop methods to analyze the potential for associated mechanical and thermal loads on the containment building, internal structures, and equipment. The detonation mode of combustion was recognized as being of key importance when considering the potential for structural damage, since the pressures associated with this mode of combustion can be significantly greater than for the other modes of combustion. Experimental and analytical studies focussed on development of the capability to predict the combination of initial conditions for which detonations are possible. This work led to development of an understanding of the detonation phenomena which allows judgements to be made on the conditions under which mixtures of hydrogen, air, and steam are likely to undergo detonations.

Since containment conditions during postulated severe accident scenarios are characterized by atmospheres of hydrogen, air, and steam at pressures between one and three atmospheres, and temperatures up to $400 \mathrm{~K}$, experimental data for detonation cell width were developed for this range of conditions $[2,3]$. Accident sequence calculations suggested, however, that under some conditions, localized containment temperatures to $700 \mathrm{~K}$ or greater [4] are possible. While there were no detonation cell size data available at these higher temperatures, application of the Zel'dovich-von Neumann-Döring (ZND) model to elevated mixture temperatures suggested that the detonation cell size decreases with temperature for most mixture compositions and, 
therefore, that the mixture sensitivity to detonation increases with initial mixture temperature [5].

Witn the availability of detailed chemical reaction mechanisms for mixtures of hydrogen, air, and steam, the ZND model has become relatively simple to implement computationally, and attempts have been made to relate the chemical reaction zone length scale predicted by the ZND model to the measured cell size. It was first proposed by Shchelkin and Troshin [6] that the experimentally measured cell could be correlated with the calculated $\mathrm{ZND}$ reaction zone length. Since then, knowledge of the detailed chemical reaction mechanisms occurring for different mixtures hās increased dramatically, especially for hydrogen-air mixtures. The availability of the reaction mechanisms led to detailed ZND analyses of hydrogen-air and hydrogen-air-diluent systems, where the diluents were steam, carbon dioxide, and nitrogen $[7,8]$.

Experimental data for the detonation cell size of hydrogen-air-steam mixtures thac were developed in the 1980s in considerable detail were for mixtures at initial temperatures in the range $300 \mathrm{~K}$ to $400 \mathrm{~K}$, pressure of one atmosphere, and compositions covering the range of approximately 10 to 60 percent hydrogen by volume. These experiments were performed in detonation test vessels of diameter in the range of $5 \mathrm{~cm}$ to $43 \mathrm{~cm}$. This data is largely summarized by Guirao, et al. [2] and by Stamps [5]. Analyses of the available experimental data indicated that the ZND model captures the effects of hydrogen concentration, diluent concentration and pressure provided that a suitable choice is made for the constant which relates the calculated chemical reaction length scale to the measured detonation cell size $[5,8]$. The combined experimental evidence and analytical modeling clearly demonstrated that the effect of steam is to dramatically increase the reaction zone length or, equivalently, the 
detonation cell size. Thus, the sensitivity to detonation of hydrogen-air mixtures is dramatically reduced by the presence of quantities of steam of 10 percent by volume or greater.

The effect of hydrogen-air mixture temperature on detonation cell size was apparently first discussed by Westbrook [7]. ZND model calculations suggested that, for stoichiometric mixtures at an initial pressure of one atmosphere, increasing the temperature from $200 \mathrm{~K}$ to $500 \mathrm{~K}$ results in increasing, although weakly, the induction length. No calculations were presented for offstoichiometric mixtures. Westbrook attributed this behavior to a combination of the effects of initial temperature on reactant concentration and on the post-shock temperature. Shepherd [8] examined the effect of temperature in the range $300 \mathrm{~K}$ to $500 \mathrm{~K}$ on reaction zone length in more detail. He found, with a result similar to that of Westbrook, that for stoichiometric mixtures of hydrogen-air at an initial pressure of one atmosphere, the effect of increasing temperature is to increase the reaction zone length. Shepherd commented that additional calculations (not shown in the paper) demonstrated that for very lean or very rich mixtures, the reaction zone length decreases with temperature when the pressure is kept fixed. Shepherd attributed the trends of cell width with temperature to a combination of effects due to post-shock temperature, chemical reaction mechanism, and mixture density.

The limited availability of experimental data within the temperature range $400 \mathrm{~K}$ to $700 \mathrm{~K}$ has precluded the ability to definitively assess the effect of temperature on the sensitivity of hydrogen, air, and steam to undergo self-sustaining detonations under some severe accident conditions. While the ZND model has been demonstrated to capture relevant aspects of the detonation phenomenon, data are required over a larger range of temperature than heretofore available, in order to provide a complete assessment of the effect of temperature. The experimental program at BNL is directed towards providing the required data. The main 
apparatus, which will be used in these studies, is a $30-\mathrm{cm}$ inner-diameter heated detonation tube which is currently under construction. Results reported here are from the Small-Scale Development Apparatus, which was built in the interim.

\section{Experimental Apparatus and Methods}

Figure 1 is a schematic diagram of the Small-Scale Development Apparatus (SSDA). The apparatus consists of three major components: (1) the test vessel, (2) the mixing chamber, and (3) the driver section. The test vessel consists of two mated, 3-meter long, 316 stainless steel tubes with a nominal inner diameter of $10 \mathrm{~cm}$. The test vessel is heated by pads of ceramicbead insulated, nichrome resistance wire, which cover the vessel wall. The heating system is capable of heating the test vessel to $700 \mathrm{~K}$ in 3.5 hours with a $\pm 14 \mathrm{~K}$ spatial uniformity.

The combustible gas mixture is produced in a 30 -liter mixing chamber by the method of partial pressures. The mixture is stirred for two minutes using a rotating impeller in order to ensure proper mixing of the gas constituents. For experiments where the hydrogen-air mixture is diluted with steam, the mixing chamber is evacuated and heated to $425 \mathrm{~K}$. Water is injected into the mixing chamber and the steam pressure is recorded. Hydrogen and air are then added to a final mixing chamber pressure of $0.3 \mathrm{MPa}$. During the time that the mixture is being prepared in the mixing chamber, the test vessel is heated and evacuated. At the appropriate time, the test mixture is blown down from the mixing chamber into the test vessel. During the blowdown, the test gas is heated to the test temperature as it passes through a radiation-heated coiled tube. The test vessel is charged to a nominal pressure of just below $0.1 \mathrm{MPa}$. 
Initiation of the detonation in the hydrogen-air-steam mixture is achieved through the transmission of a detonation from an acetylene-oxygen driver. The detonation is initiated in the driver gas mixture using an exploding wire circuit with a $20 \mu \mathrm{f}$ capacitor charged to $7 \mathrm{kV}$. The acetylene and oxygen gases are mixed in two $12.5-\mathrm{mm}$ diameter tubes before entering into the test vessel. The oxygen is introduced into these tubes via a central 6-mm tube, and the acetylene is introduced through the annular space between the $6-\mathrm{mm}$ and $12.5-\mathrm{mm}$ tubes. Using this system, driver slugs of any length and composition can be produced by adjustment of the relative constituent flow rates and fill time. Typically, the oxygen to acetylene ratio was about five, and effective slug lengths between 20 and $40 \mathrm{~cm}$ were used.

Eighteen equally spaced instrument ports are located along the entire length of the test vessel. Detonation pressure is measured using flush-mounted, $1 \mu$ s risetime piezoelectric water-cooled pressure transducers. Detonation time-of-arrival is measured by ionization probes. Signals from the pressure transducers and ionization probes are captured and stored on a digital $314 \mathrm{~L}$ LeCroy oscilloscope. The experiment is run remotely from an adjacent control room. All valves shown in Fig. 1 are pneumatically actuated bellows type. All experimental control and monitoring is performed using Strawberry Tree Workbench software and hardware installed on a 486 Gateway 2000 PC.

Cell size is measured using the well known smoked-foil technique (e.g., ref. 2). The foil was constructed of $0.5-\mathrm{mm}$ thick aluminum sheet metal which was cut into sections $0.3-\mathrm{m}$ wide by 0.9-m long. For temperatures above $400 \mathrm{~K}$, the best results were obtained by coating the aluminum foil with a very thin layer of Dow Corning DC200 silicone fluid before coating the foil with soot. 


\section{Results and Discussion}

In this section, experimentally measured detonation cell sizes are reported for a range of hydrogen-air-steam mixtures at vaı us temperatises. The experimental results are compared with theoretical predictions using the one-dimensional ZND model. The computer program used in the present calculations was developed by Shepherd [8]. The program requires initial mixture composition, pressure, and temperature and Chapman-Jouget (CJ) detonation velocity. The CJ detonation velocity is obtained using the chemical equilibrium code STANJAN [9]. The cell size is taken to be proportional to the calculated reaction zone length. The reaction zone length is taken to be the distance downstream from the incident shock wave to the point in the reaction zone where the temperature gradient is a maximum, which corresponds to the point where the energy release is a maximum.

In general, the cellular structure observed in hydrogen-air mixtures can be considered to be fairly "irregular," in the sense that there is a visible variation in cell size and shape over the foil. Moen et al. [10] outlined two methods for measuring the average cell size from a smoked foil. The first method is to identify and measure a large number of cells and then simply take the average. In this method, there is a substantial amount of judgment required in choosing the appropriate cells, considering the existence of substructure and the general irregularity in the cells. The second method abstracts away the cell, and thus the subjectivity of identifying a cell, and bases the cell size on the distance between diagonal parallel lines. In general, the longest lines with the most contrast are chosen as prime candidates. There still remains some subjectivity in choosing the lines. However, the authors believe the amount of judgment required in this method is much less than with the first method. As a result, the second 
method, often referred to as the "dominant mode method" was used in this study to determine the average cell width.

It is very difficult to assign uncertainty bounds for detonation cell width measurements. In this study, image analysis, similar to that performed by Lee [11], was performed on a limited number of the foils in order to quantify the variation in cell size about the mean. A general observation is that the standard deviation, representing the variation in the cell size, increases with the average cell size. The variation in the cell size, as characterized by the standard deviation, varies from a low of about \pm 3 percent of the average cell size for 30 percent hydrogen to a high of \pm 55 percent for the 20 percent hydrogen mixture. This is comparable to the \pm 25 percent spread in the measured average cell size reported by Tieszen [3].

\section{Cell Size Measurements at Room Temperature}

Detonation experiments were initially performed at $300 \mathrm{~K}$ with several objectives in mind: (1) to compare with existing experimental data, (2) to check instrumentation, and (3) to develop and refine operating procedures. In order for experimentally obtained cell size data to be meaningful, it is imperative that the detonation propagate under steady-state conditions as it passes over the smoked foil. Therefore, all memory of the initiation should be gone and the detonation wave should propagate at a constant velocity very close to the $\mathrm{CJ}$ detonation velocity. In the present experiments, the acetylene-oxygen driver worked very well and the detonation wave, initially overdriven, quickly settled to a constant velocity. The average detonation velocity measured over the last half of the vessel was about 2 percent of the $\mathrm{CJ}$ detonation velocity. 
Cell size data obtained for hydrogen-air mixtures at $300 \mathrm{~K}$ and $0.1 \mathrm{MPa}$ are plotted in Fig. 2. The data, displayed as cell size versus hydrogen concentration, result in a typical " $U$ "-shaped curve. Only data from those experiments where at least three transverse cells spanned the vessel inner-circumference are plotted. Experimental cell size data obtaıned at McGill University [2] and from the Heated Detonation Tube (HDT) at Sandia National Laboratory [3] are also shown in Fig. 2. The McGill data was obtained in 5- and 15-cm diameter tubes and the Sandia HDT is $43 \mathrm{~cm}$ in diameter. The McGill data covers the complete range of hydrogen mixtures tested in the SSDA. In general, the McGill data appears to give slightly larger cell size, as compared to the SSDA data, over the entire range of mixture composition. For example, the cell size obtained at stoichiometric conditions (i.e., 30 percent hydrogen) from the SSDA is about $1 \mathrm{~cm}$ as compared to $1.5 \mathrm{~cm}$ obtained from the McGill $5-\mathrm{cm}$ diameter rube. There is much better agreement for the lean mixtures. Unfortunately, the HDT data does not cover the entire range of hydrogen mixtures tested in the SSDA. The HDT data for lean hydrogen-air mixtures correlates very well with both the SSDA and McGill data. Cell size measurements from HDT reported at stoichiometric conditions agree with the data from the SSDA. The slightly larger cell sizes reported by the McGill researchers could possibly be attributed to water vapor in the test mixture resulting from the use of atmospheric air; dry bottled air was used in both the SSDA and HDT experiments. The weakest mixture which could be detonated, resulting in a single-head spin, was 15 percent hydrogen.

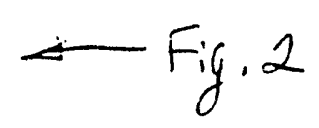

Figure 2 also shows the ZND model prediction for cell size as a function of hydrogen concentration. As discussed above, the theoretical cell size is obiained by using the ZND model to calculate the reaction zone length, 1 , for a given mixture and initial conditions. This calculated reaction zone length is multiplied by a constant, $A$, to give the cell size. This value of the constant is obtained by anchoring the predicted cell size data to one of the experimentally 
measured cell size data points. The choice of which experimental point is arbitrary. For the present study, 30 percent hydrogen was chosen as the mixture to anchor the theoretical data. This yields a constant of proportionality, between the calculated reaction zone thickness and the cell size, of 51 . The general trend in the experimental data is very well predicted by the ZND model. Quantitatively, the model predictions and the experimental data for the cell width for hydrogen concentrations between 25 and 50 percent are very good. However, outside this range, the model predictions begin to deviate from the experimental data.

\section{Effect of Temperature on Cell Size}

The effect of temperature on cell size was investigated by performing two series of experiments covering a wide range of hydrogen concentration at nominal temperatures of $500 \mathrm{~K}$ and $650 \mathrm{~K}$. Loading of the test mixture at temperatures above $650 \mathrm{~K}$ resulted in the prompt ignition and burning of the mixture. Cell size data obtained for hydrogen-air mixtures at $500 \mathrm{~K}$ and $650 \mathrm{~K}$ are shown in Figs. 3 and 4, respectively. Again, only the data where three or more transverse cells are recorded on the smoked foil are presented. The hydrogen concentrations varied from a low of 13.8 percent to a high of 50 percent for the series performed at $500 \mathrm{~K}$ and between 10 and 50 percent hydrogen at $650 \mathrm{~K}$. Also shown in these figures are the ZND model predictions using the same constant of proportionality used to anchor the prediction at $300 \mathrm{~K}$ (i.e., $\mathrm{A}=51$ ). As in the $300 \mathrm{~K}$ series shown in Fig. 2, the ZND model does a good job in predicting the qualitative features of the data. Quantitatively, the model predictions at $500 \mathrm{~K}$ are better than that at $650 \mathrm{~K}$ where the model tends to overestimate the cell size over the entire range of mixtures tested.

The effect of temperature on cell size is best seen in Fig. 5. The cell size data for hydrogen-air

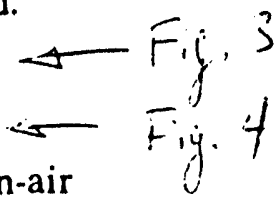
at $300 \mathrm{~K}$ and $650 \mathrm{~K}$ from Figs. 2 and 4 is replotted in Fig. 5. From this graph, it is clear that 
temperature has little effect on cell size for mixtures between 25 and 45 percent hydrogen. For mixtures outside this range, increasing the mixture temperature tends to decrease the measured detonation cell size. This effect is also predicted by the ZND model.

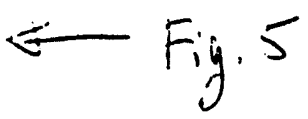

The onset of single-head spin at $500 \mathrm{~K}$ and $650 \mathrm{~K}$ was observed in mixtures containing 11.5 and about 9 percent hydrogen, respectively. These concentrations correspond to the lean detonation limits for the 10-cri diameter SSDA detonation tube.

\section{Volumetric Oxidation at Elevated Temperatures}

At $500 \mathrm{~K}$, the average detonation velocity was measured to be in good agreement with the CJ detonation velocity as was the case at $300 \mathrm{~K}$. However, at $650 \mathrm{~K}$, the average velocity was found to be consistently below the $\mathrm{CJ}$ detonation velocity with a maximum deviation of 5 percent for 50 percent hydrogen mixtures. It was posiulated that this measured sub-CJ detonation velocity at $650 \mathrm{~K}$ was an indication that the mixture was slowly reacting. This was verified qualitatively by loading the mixture into the vessel at $650 \mathrm{~K}$ and observing a pressure drop over time. In later tests, gas samples were taken at various times after the mixture was loaded and analyzed using a gas chromatograph. At $500 \mathrm{~K}$, there was no detectible reduction in hydrogen concentration. At $650 \mathrm{~K}$, typically over a five minute period the hydrogen mole fraction decreased by about 10 percent for an initial 50 percent hydrogen mixture and about 25 percent for an initial 15 percent hydrogen mixture. 


\section{Effect of Steam on Cell Size}

In most LWR severe accident scenarios, a large amount of steam is released into containment along with the hydrogen. For this reason, a series of tests were pe:formed to measure the effect of steam on the detonation cell size of hydrogen air mixtures at different temperatures. The results from these experiments are shown in Fig. 6 . In all tests with steam, the hydrogen-to-air ratio was that for stoichiometric conditions. The steam fraction was varied from 10 to 30 percent, in steps of 5 percent, and the tests were done at temperatures of $400 \mathrm{~K}, 500 \mathrm{~K}$, and 650K. In all cases, the steam is under superheat conditions. Also plotted in Fig. 6 is the calculated cell size using the ZND model.

The ZND model predictions reproduce the general trend of the data satisfactorily. Three data points obtained from the HDT at Sandia are also included for comparison purposes. These experiments were performed at a mixture temperature of roughly saturation conditions (i.e., 373K). The 15 and 20 percent steam fraction data can be compared directly with the SSDA data. The smallest steam fraction reported in the HDT data is $\mathbf{1 1 . 5}$ percent, which is also shown in Fig. 6. This can be compared to the 10 percent data from the SSDA. In general, the agreement between the SSDA and HDT data is very good.

From Fig. 6, one can deduce the relative effect of steam on the mixture sensitivity. As one would expect, at a given temperature, as the steam fraction is increased the cell size also increases. This is due to the effect of reduced post-shock mixture temperature, due to the high heat capacity of steam on chemical reaction rates behind the leading shock. The steam thus desensitizes the mixture. As the mixture temperature increases, this desensitizing effect from the steam becomes less prominent. It appears that at very high temperatures, greater than 
$650 \mathrm{~K}$, the cell size for the various steam fraction converge and the desensitizing effect of the steam is lost.

\section{Conclusions}

The Small-Scale Development Apparatus (SSDA) was developed as the first phase of the BNL High-Temperature Hydrogen Combustion Research Program. The objective of the SSDA was to provide preliminary experimental data to characterize the sensitivity of hydrogen-air-steam mixtures to undergo detonations at elevated temperature.

The following conclusions have been reached on the basis of the experimental data and analysis presented in this report:

1. Detonation cell size measurements provide clear evidence that the effect of hydrogen-air gas mixture temperature, in the range $300 \mathrm{~K}-650 \mathrm{~K}$, is to decrease cell size and, hence, to increase the sensitivity of the mixture to undergo detonations. Initial pressure was $0.1 \mathrm{MPa}$ in all experiments.

2. Increasing the steam content, in the range of zero to 30 percent by volume, of a stoichiometric hydrogen-air mixture increases the cell size and thus decreases its sensitivity to detonate. However, at elevated temperature, this desensitizing effect becomes less pronounced. 
3. The hydrogen-air detonability limits for the $10-\mathrm{cm}$ inside diameter SSDA test vessel, based upon the onset of single-head spin, decreased from 15 percent hydrogen at $300 \mathrm{~K}$ down to about 9 percent hydrogen at $650 \mathrm{~K}$.

4. The one-dimensional ZND model does a very good job at predicting the overall trends in the cell size data over the range of hydrogen-air-steam mixture compositions and temperature studied in the experi..ents. 


\section{Acknowledgements}

The authors would like to thank Professor J. Shepherd (California Institute of Technology) for the use of his ZND code. The input and suggestions by both Professors J. Shepherd and J. Lee (McGill University) acting as consultants on the project are much appreciated. We would also like to thank L. Gerlach for doing the bulk of the work on the apparatus and to C. Finfrock for aiding in the running of the experiments. The BNL High-Temperature Hydrogen Combustion Research Program is a research effort sponsored by the U.S. Nuclear Regulatory Commission, the Japanese Nuclear Power Engineering Corporation, and BNL. 


\section{References}

1. Toth, L.M., et al., Ed., "The Three-Mile Island Accident, Diagnosis and Prognosis," American Chemical Society Symposium Series, No. 293, 1985.

2. Guirao, C.M., Knystautas, R, Lee, J.H., "A Summary of Hydrogen-Air Detonation Experiments," NUREG/CR-4961, SAND87-7128, 1989.

3. Tieszen, S.R., Martin, P.S., Bennedick, W.B., Berman, M., "Detonability of H2-AirDiluent Mixtures," NUREG/CR-4905, SAND85-1263, 1987.

4. Yang, J. W., "High-Temperature Combustion in LWR Containments Under Severe Accident Conditions," Brookhaven National Laboratory, Technical Report L-1924 1/17/92, 1992.

5. Stamps, D. W., et al., "Hydrogen-Air-Diluent Detonation Study for Nuclear Reactor Safety Analyses," Sandia National Laboratories, NUREG/CR-5525, SAND89-2398, 1991.

6. Shchelkin, K. I., and Troshin, Y. K., Gas Dynamics of Detonations, Mono Book Corp., Baltimore, Maryland, 1965.

7. Westbrook, C.K. and Urtiew, P.A., "Chemical Kinetics Prediction of Critical Parameters in Gaseous Detonations," Nineteenth Symposium (International) on Combustion, The Combustion Institute, Pittsburgh, 1982, pp. 615-623.

8. Shepherd, J. E., "Chemical Kinetics of Hydrogen-Air-Diluent Detonations," Progress in Astronautics and Aeronautics, J.R. Bowen, et al., eds., 1986, Vol. 106, p. 263.

9. Reynolds, W.C., "The Element Potential Method for Chemical Equilibrium Analysis: Implementation in the Interactive Program STANJAN Version 3," Dept. of Mechanical Engineering, Stanford University, Palo Alto, California, January 1986.

10. Moen, I.O., Murray,S.B., Bjerketvedt, D., Rinnan, A., Knystataus, R., and Lee, J.H., "Diffraction of Detonation From Tubes Into a Large Fuel-Air Explosive Cloud," Nineteenth Symposium (International) on Combustion, The Combustion Institute, Pittsburgh, 1982, p. 635.

11. Lee, J, "Digital Signal Processing Analysis of Soot Foils," Progress in Astronautics and Aeronautics, A. L. Kuhl, et al., eds., 1993, Vol. 153, p. 182. 


\section{Figure Captions}

1 Schematic diagram of the Small-Scale Development Apparatus

2 Average detonation cell size for hydrogen-air mixtures at $300 \mathrm{~K}$ and $0.1 \mathrm{MPa}$

3 Average detonation cell size for hydrogen-air mixtures at $500 \mathrm{~K}$ and $0.1 \mathrm{MPa}$

4 Average detonation cell size for hydrogen-air mixtures at $650 \mathrm{~K}$ and $0.1 \mathrm{MPa}$

5 Effect of temperature on the average detonation cell size for hydrogen-air mixtures at $0.1 \mathrm{MPa}$. Data for 300K from Fig. 2 and for 650K from Fig. 4.

6 Effect of temperature on the average detonation cell size for stoichiometric hydrogen-air and steam mixtures at $0.1 \mathrm{MPa}$. Lines denote $\mathrm{ZND}$ model predictions. HDT data from Reference 3. 


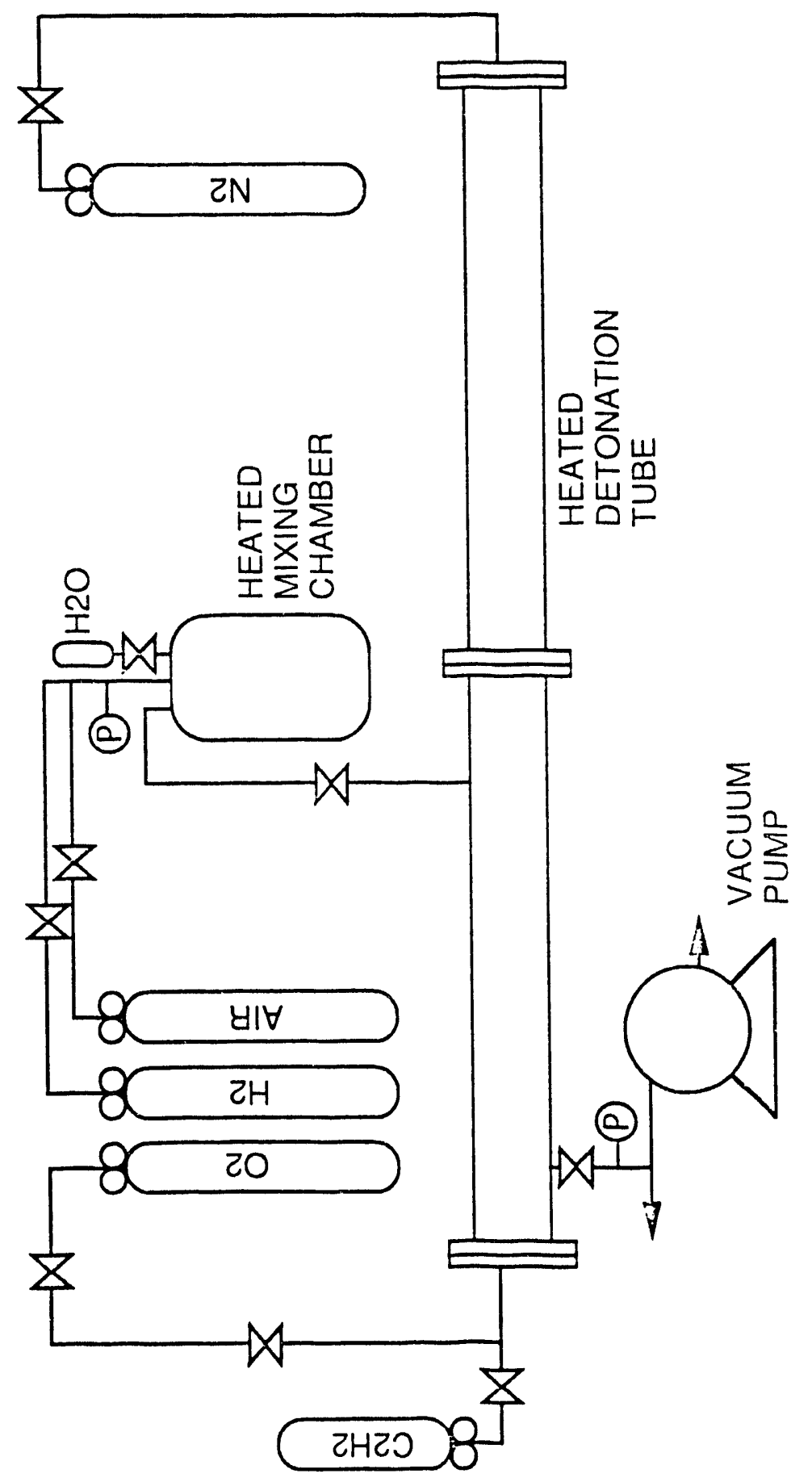

1 


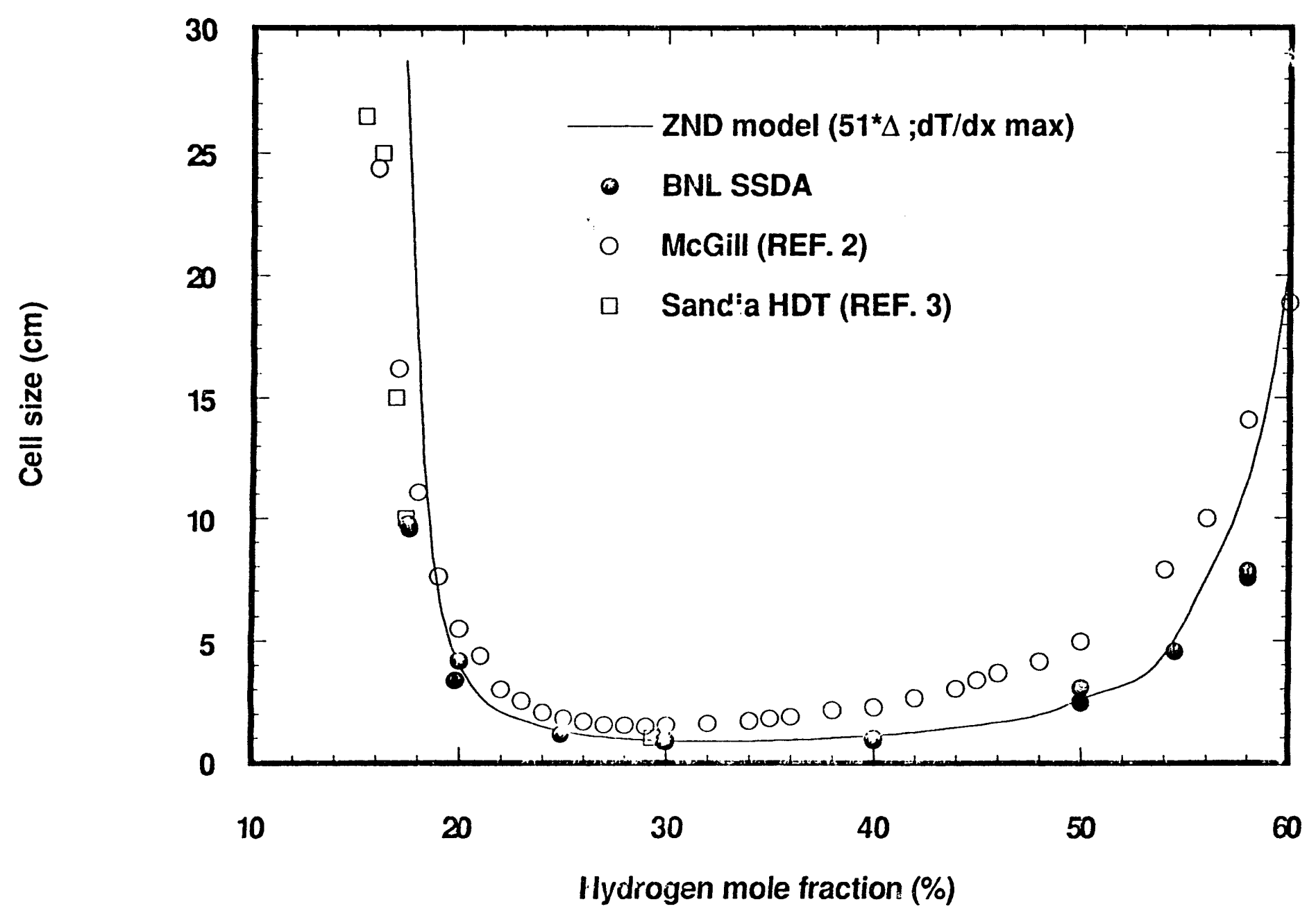

Fig. 2 


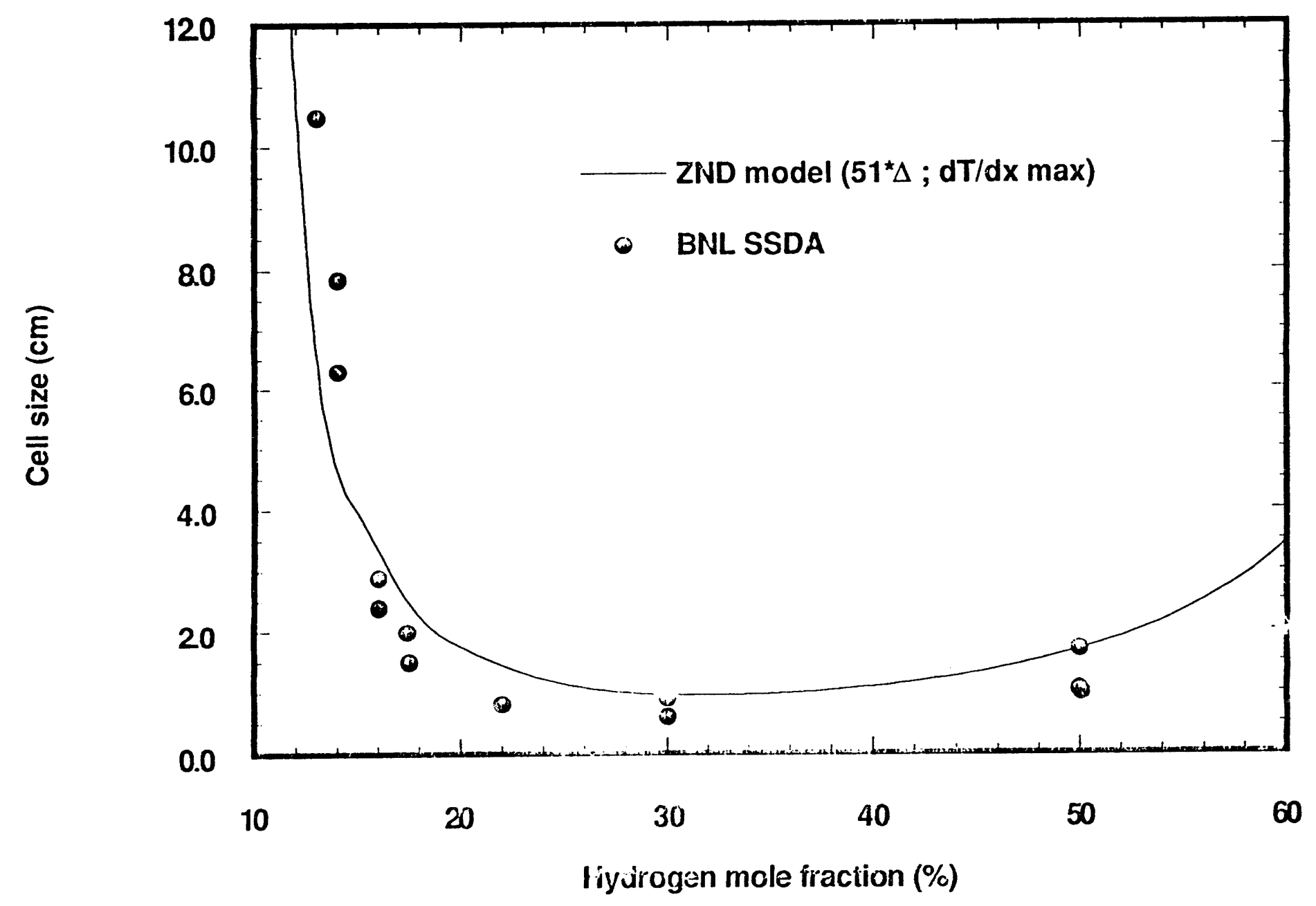

Fig. 3 


$$
\text { t) } b ! \pm
$$

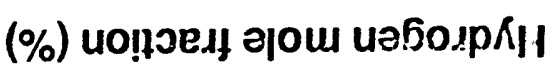

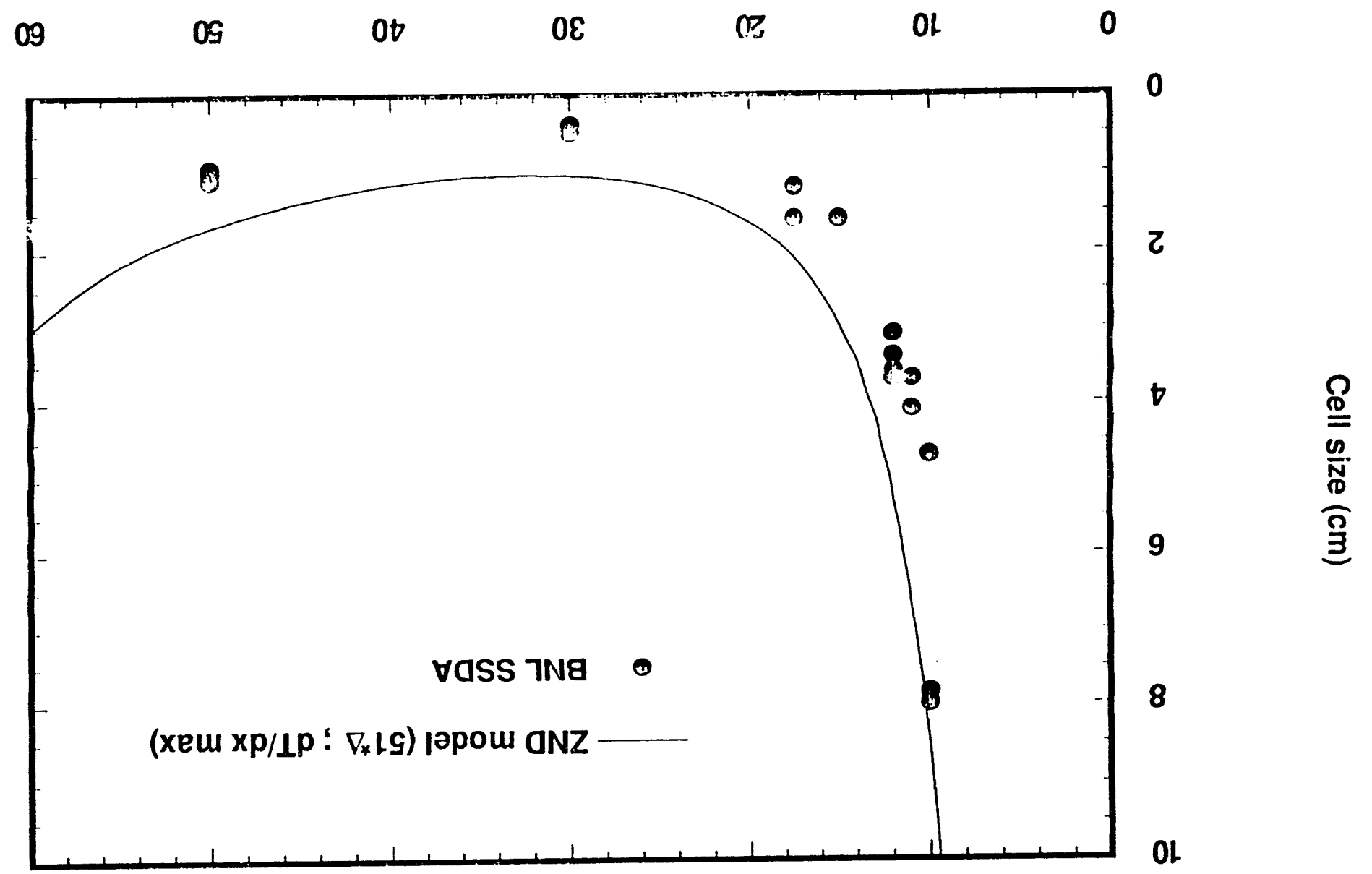




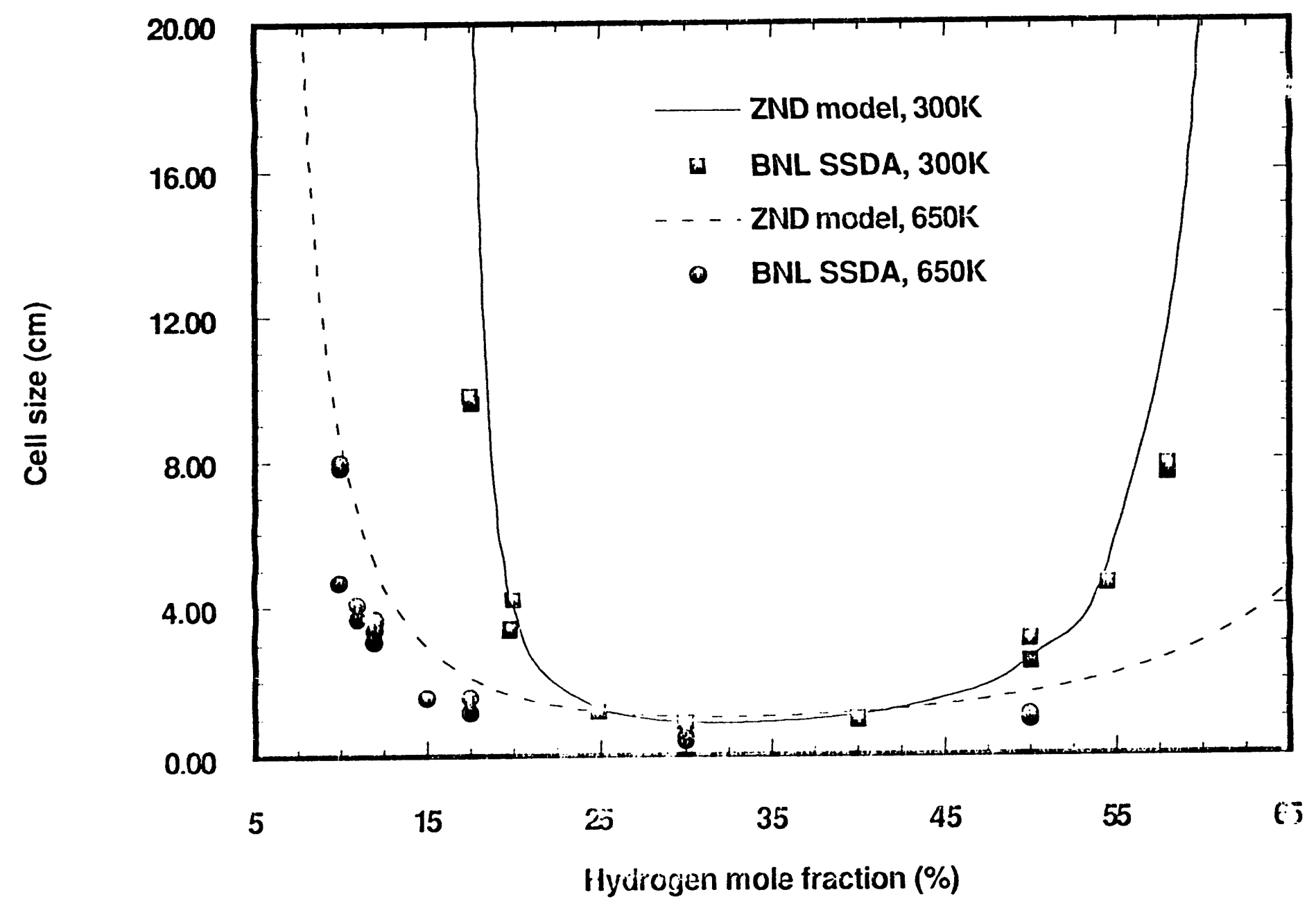

Fig. 5 


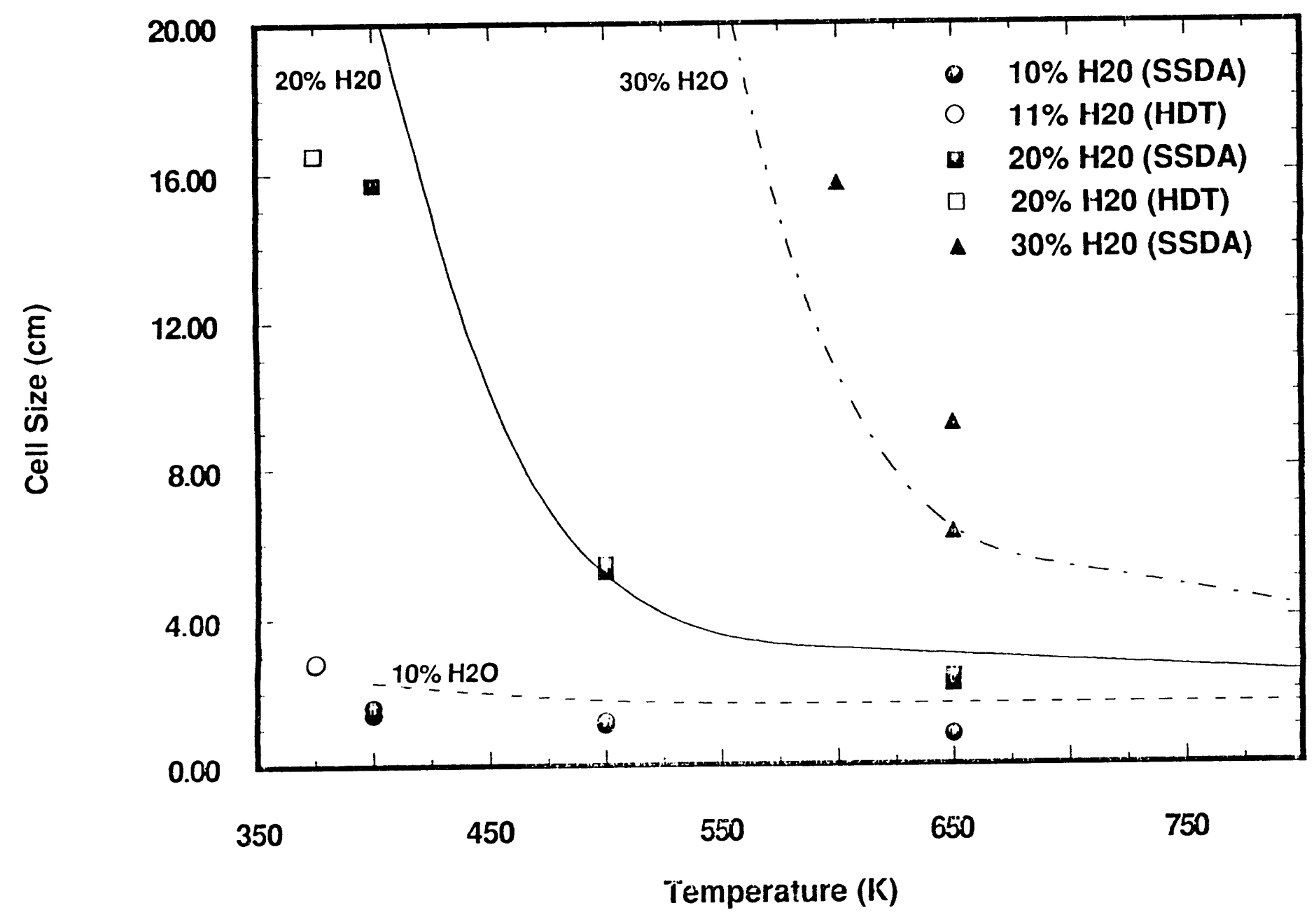

Fig. 6 

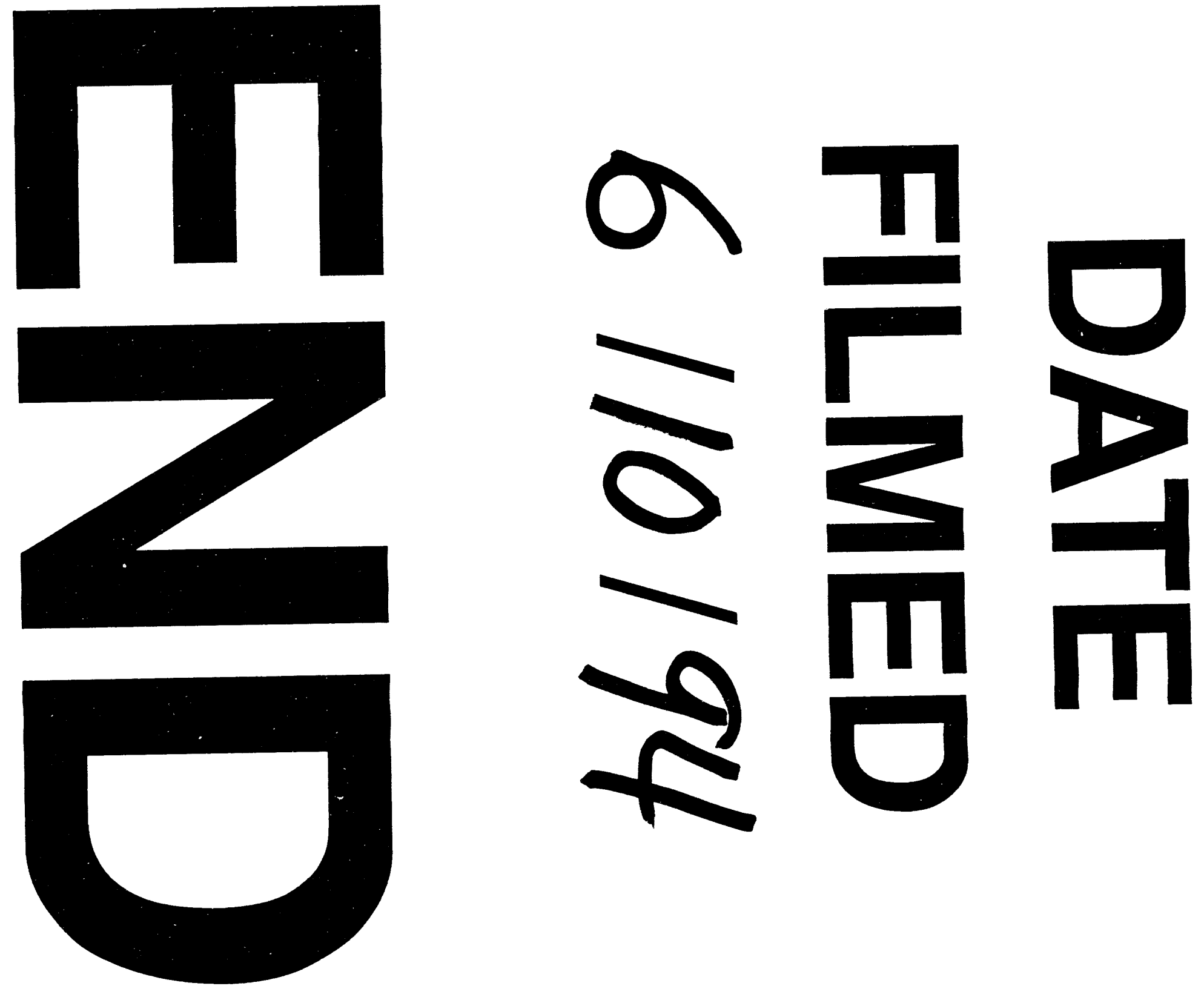